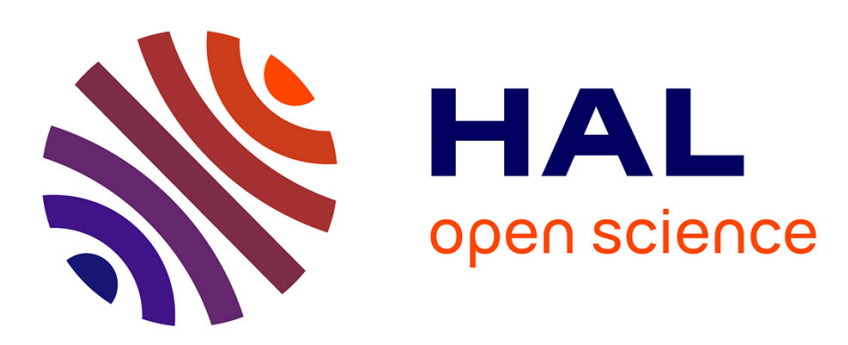

\title{
An experimental study of local heat transfer using high Prandtl number liquid jets
}

Clément Renon, Matthieu Fénot, Manuel Girault, Stéphane Guilain, Bassel Assaad

\section{- To cite this version:}

Clément Renon, Matthieu Fénot, Manuel Girault, Stéphane Guilain, Bassel Assaad. An experimental study of local heat transfer using high Prandtl number liquid jets. International Journal of Heat and Mass Transfer, 2021, 180, pp.121727. 10.1016/j.ijheatmasstransfer.2021.121727 . hal-03435681

\section{HAL Id: hal-03435681 https://hal.science/hal-03435681}

Submitted on 18 Nov 2021

HAL is a multi-disciplinary open access archive for the deposit and dissemination of scientific research documents, whether they are published or not. The documents may come from teaching and research institutions in France or abroad, or from public or private research centers.
L'archive ouverte pluridisciplinaire HAL, est destinée au dépôt et à la diffusion de documents scientifiques de niveau recherche, publiés ou non, émanant des établissements d'enseignement et de recherche français ou étrangers, des laboratoires publics ou privés. 


\title{
Title: An experimental study of local heat transfer using high Prandtl number liquid jets
}

Clément Renon $^{1,2}$, Matthieu Fénot ${ }^{1}$, Manuel Girault ${ }^{1}$, Stéphane Guilain ${ }^{2}$, Bassel Assaad ${ }^{2}$

1. P' Institute, CNRS, ENSMA, University of Poitiers, UPR 3346, 1 Avenue Clément Ader, BP 40109, 86961Futuroscope Chasseneuil, France.

2. Renault S.A.S, Technocentre, 1 Avenue du Golf, 78280 Guyancourt, France

\begin{abstract}
An experimental investigation was performed to determine the local value of heat transfer coefficient with a free-surface axisymmetric downward jet of lubricating oil impinging on a fixed plate. A large range of Prandtl numbers was considered $(148<\operatorname{Pr}<925)$ in order to fill a data gap on highly viscous fluids, especially regarding local measurements. In the range of Reynolds numbers considered $(170<R e<2225)$, dependencies similar to the literature were identified for laminar and turbulent regimes. A significant influence of the injector diameter (1, 2 and $4 \mathrm{~mm})$ on exchanges was found, but nozzle-to-target distances $(5<z / d<20)$ showed no particular effect. Local and mean values of the Nusselt number were correlated by taking into account the above-mentioned parameters. Nevertheless, data exploitation showed that the warming of the thin liquid film over the plate, which is dependent on the heating flux to evacuate, should be taken into account for viscous fluids such as oils; the induced changes of viscosity lead to divergencies in measured heat exchanges. A methodology based on empirical observation was developed to take this phenomenon into consideration.
\end{abstract}

Keywords: Impinging liquid jet; Local heat transfer; High Prandtl number fluid; Oil; Infrared thermography; Electric machine cooling 


\section{Nomenclature}

Cp Fluid specific heat capacity

$d \quad$ Nozzle diameter

$d_{\text {ref }}=2 \mathrm{~mm}$ Reference diameter used in this study

$e \quad$ Plate thickness

$h \quad$ Heat transfer coefficient on the impinged side

$h_{n a t} \quad$ Natural heat transfer coefficient on the backside

$l=3 \mathrm{~mm}$ Length of the end part of the injector

$\mathrm{Nu} \quad=h d / \lambda_{f}$ Nusselt number

$N u_{\varphi=0} \quad$ Nusselt number on the impinged side obtained for a non-heated fluid

$N u_{\text {avg }}(r)=2 \pi \int_{0}^{r} N u r d r$ averaged Nusselt number on a disk of radius $r$

$N u_{s t g} \quad$ Nusselt number at stagnation point

$\operatorname{Pr} \quad=\mu C p / \lambda_{f}$ Prandtl number

$r \quad$ Distance to stagnation point

$\operatorname{Re} \quad=\rho V d / \mu$ injection Reynolds number

$S \quad=3.14 \mathrm{~cm}^{2}$ Surface of the work area

$T_{a m b} \quad$ Ambient air temperature

$T_{a w} \quad$ Adiabatic wall temperature

$T_{\text {backside }}$ Wall temperature on the backside
$T_{i n j} \quad$ Jet injection temperature

$T_{\text {ref }} \quad$ Jet reference temperature

$T_{w} \quad$ Wall temperature on impinged side

$u_{r} \quad$ Local mean velocity in the radial direction

$V_{j} \quad$ Average injection velocity

$z \quad$ Nozzle-to-plate distance

\section{Greek symbols}

$\lambda_{f} \quad$ Fluid thermal conductivity evaluated at injection temperature

$\lambda_{s} \quad$ Target plate thermal conductivity

$\mu \quad$ Fluid dynamic viscosity evaluated at injection temperature

$\mu_{a w} \quad$ Fluid dynamic viscosity evaluated at adiabatic wall temperature

$\mu_{w} \quad$ Fluid dynamic viscosity evaluated at wall temperature

$\rho \quad$ Oil density evaluated at injection temperature

$\sigma \quad$ Oil surface tension evaluated at injection temperature

$\varepsilon \quad$ Target plate emissivity

$\varphi_{\text {conv }} \quad$ Convective flux on the impinged side

$\varphi_{\text {elec }} \quad$ Electric heating flux

$\varphi_{\text {loss }} \quad$ Loss flux 


\section{Introduction}

The recent advent of electric and hybrid vehicles in the automotive sector has given rise to more effective and reliable motors. The power density of the motor is enhanced, leading to higher local thermal constraints. Consequently, innovative cooling-system concepts are being considered, using lubricating oil jets, which are more efficient than traditional air systems; contrary to water cooling, they directly cool critical parts [1-4]. Due to its high-density heat removal capacities, jet impingement has been employed for many years in other industrial applications ranging from metal processing to piston or electronic chipset cooling.

Free-surface liquid jet impingement has been widely studied over recent decades. Analytic works based on Watson's laminar boundary model [5] were authored by [6-8] and described heat transfer under a laminar and axisymmetric jet. Five distinct zones were used to describe the flow and exchange on the plane, including a stagnation zone where normal speed drops in favour of radial speed, parallel to the plate, three wall-jet zones describing the establishment of the viscous boundary layer and then the thermal one (for fluids with $\operatorname{Pr}>1$ ) and, finally, the hydraulic jump, consisting in a prompt increase of film thickness. Numerous experimental and numerical studies have confirmed these results [9-12].

The heat exchanges using water jets studied by Elison and Webb [13] showed a $R e^{0.5}$ and $R e^{0.8}$ dependence for turbulent and laminar flows respectively. They attribute this difference to surface tension forces at nozzle exit. By measuring local exchanges on turbulent water flows, Stevens and Webb [14] obtained similar dependence results, as did several other authors [1517] for oil. However, some studies have found a Reynolds exponent close to 0.5 even in laminar cases $[9,18,19]$. Classical $\operatorname{Pr}^{1 / 3}$ dependence for heat exchanges fits fairly well with experimental data (using water or oil) $[16,18,20,21]$ even though some studies have found slight discrepancies. Using water jets $(\operatorname{Pr} \approx 10)$, Stevens and Webb [14] found $\operatorname{Pr}^{0.4}$ dependence, as did Liu et al. [9] $(0.15<\operatorname{Pr}<3)$. Concerning oil jets, [15,17,19] suggested less dependence $\left(\operatorname{Pr}^{0.239-0.32}\right)$, but Easter et al. [22], who presented the widest Prandtl number range to our knowledge $(90<\operatorname{Pr}<750)$, found that the 0.4 exponent correlated well with their results.

In addition, nozzle geometry has a key role in convective exchanges and can be a source of some of the disparities observed in the literature. With regard to turbulent water jets, Pan et al. [23] found differences of approximately $40 \%$ on heat transfer by using different injector types (from the more to the less efficient : fully developed pipe nozzle, sharp-edged orifice and contoured orifice). On the basis of laser Doppler velocimetry measurements, they attributed these differences to the velocity gradient and turbulence level. They also introduced the radial 
dimensionless velocity gradient $G=d\left(u_{r} / V\right) / d(r / d)$, where $u_{r}$ is the local mean velocity in the radial direction (cf figure 2) and $V$ the average jet velocity at the exit of the injector, and successfully used this parameter to correlate their thermal results, but only for one diameter and one nozzle-to-plane impact distance $(z / d=1)$. Using oil, Ma et al. [18] found that small pipes yielded exchanges up to $18 \%$ higher than orifice nozzles (perforated plate) at stagnation zone. Experimental studies conducted by $[11,14,24,25]$ with water and oil jets showed that the Reynolds number is not sufficient to fully account for injector diameter changes, as a larger diameter leads to better cooling. For Fitzgerald and Garimella [24], who carried out laser Doppler velocity measurements on submerged water jets, that is because a larger diameter maintains higher levels of turbulence and higher centerline normalized velocities. Many characteristic numbers have been used to assess the influence of the diameter, without any clear consensus : $V / d$, to take account of the velocity gradient near the stagnation zone (like $G$, it is complex to obtain experimentally) [14], the Bond number $B o=g \rho d^{2} / \sigma$, representing the ratio of gravity forces to surface tension forces [25], or simply the diameter $d$, generally as a dimensionless number using the diameter of the area considered when averaging the Nusselt number $[15,17,19]$. Concerning nozzle-to-target distance, small length $(z / d<1)$ alters the flow field downstream of the stagnation point and consequently affects heat transfers, while long distance $(z / d>20)$ can change a parabolic velocity profile into a uniform one, leading to a drop of cooling capacities, as pointed out by Lienhard [21]. However, most experimental studies $[11,13,14,17-19]$ agree that nozzle-to-target spacing between these two boundaries has very limited impact.

In the surveys on liquid jets, however, the focus has been on water rather than high-Prandtl oil as working fluid. In addition, most oil jet studies have only provided average data over a disk. The main purpose of this experimental investigation is to fill the data gap regarding local heat transfer of highly viscous jets with higher Prandtl numbers than those previously studied. By monitoring the flow rate and the injection temperature of the fluid $\left(18^{\circ} \mathrm{C}\right.$ to $\left.70^{\circ} \mathrm{C}\right)$, a wide range of Prandtl numbers $(148<\operatorname{Pr}<925)$ and Reynolds numbers $(170<R e<2225)$ were studied. Moreover, for several measurement points, three different injector diameters $(d=$ $1 ; 2 ; 4 \mathrm{~mm})$ and three nozzle-to-target distances $(z / d=5 ; 10 ; 20)$ were used. As a result, this experimental study deals with 41 different configurations. 


\section{Experimental apparatus}

Figure 1 schematically illustrates the apparatus used in this research. Oil is driven in a closed loop, consisting in an adjustable injection, a heated impinging plate, and a temperature and flow rate control and measurement apparatus including an IR camera. Oil is stored in a tank connected to a $100 \mu \mathrm{m}$ filter to prevent oil impurities. One of the ATF (Automatic transmission fluid) oils was used in our experiments. In order to vary fluid viscosity and the injection Prandtl number, oil temperature is monitored by a dynamic temperature control system (Huber Unistat 410w). Great attention was paid to inlet temperature stability. After any change of parameters (flow rate, inlet temperature), the flow in the injection system was maintained long enough (around $1 \mathrm{~h}$ ) to obtain a stable inlet temperature (measured temperature fluctuations were lower than $\pm 0.05 \mathrm{~K}$ ). In addition to the internal pump of the thermostat, a voltage-controlled $24 \mathrm{~V}$ gear pump regulates the flow rate. A by-pass connected to the tank was included to allow the pump to work at optimal operating state. The other conduit located close to the 3-way valve leads to the test section through an ultrasound flow meter. Its measurement range is 0.1 to $15 \mathrm{~L} / \mathrm{min}$, with random uncertainty of $\pm 7.2 \mathrm{~mL} / \mathrm{min}$. Injection temperature was also measured by a platinum resistance thermometer (PT100 class A) located as close as possible to the nozzle (7). Hence, the injection Prandtl and Reynolds numbers could be calculated considering the injector geometry and oil property tabulations.

In the test section, the nozzle holder, facing downward, can be translated vertically to change the distance $\mathrm{z}$ with the target plate, using a nozzle adjustment collar. A tapped hole at the edge of the tube allows the injector to be changed in order to study various diameters $(1,2$ and $4 \mathrm{~mm}$ ). Injection diameters are normalized by a reference diameter $d_{r e f}=2 \mathrm{~mm}$ in correlations. Due to industrial and experimental constraints, the length of the end part of the injector is constant for each nozzle: $l=3 \mathrm{~mm}$. Indeed, this leads to a $(l / d)$ ratio between $0.75 d$ and $3 d$. The jet impinges a square horizontal heated plate (detailed view on figure 2), surrounded by a channel collecting the oil in four tubes connected to the main tank. This evacuation channel is located slightly below the heated plate to make sure that it does not disturb upstream flow. 


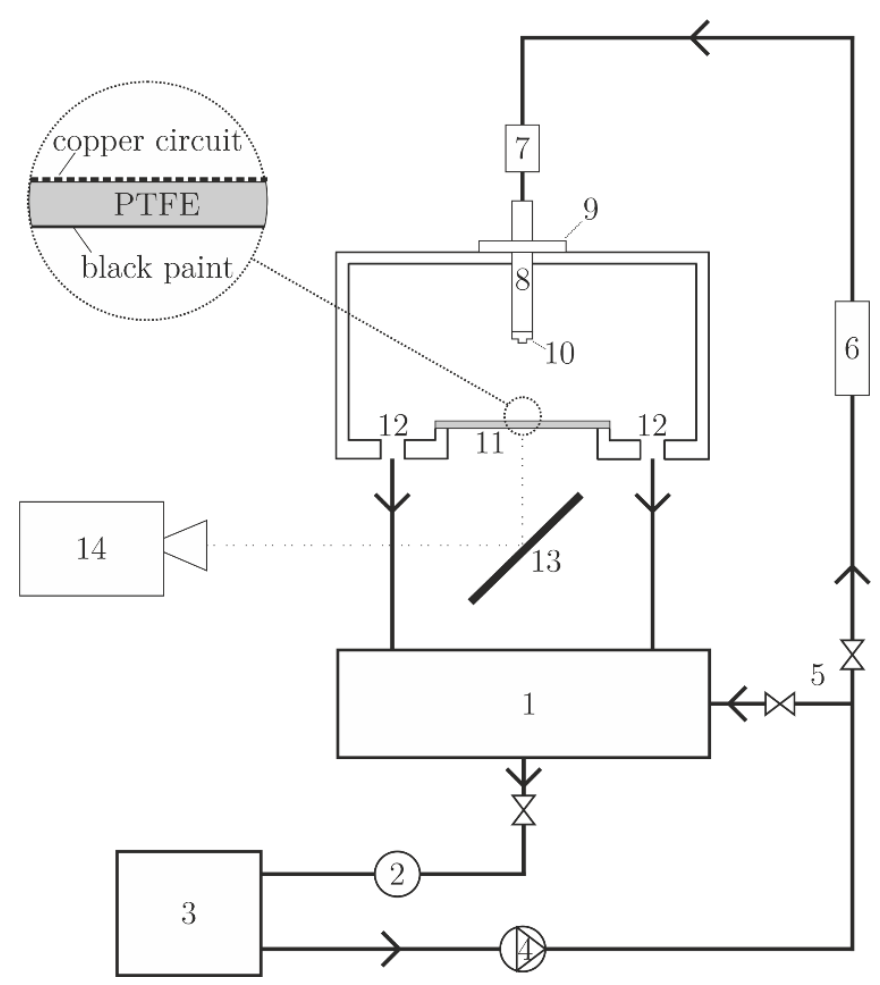

Fig. 1. Schematic view of the experimental apparatus for thermal measurements: (1) tank; (2) filter; (3) thermostat; (4) gear pump; (5) bypass; (6) ultrasound flow-meter; (7) platinum resistance thermometer; (8) nozzle holder; (9) nozzle adjustment collar; (10) nozzle; (11) target plate; (12) evacuation channel; (13) golden mirror; (14) infrared thermal camera
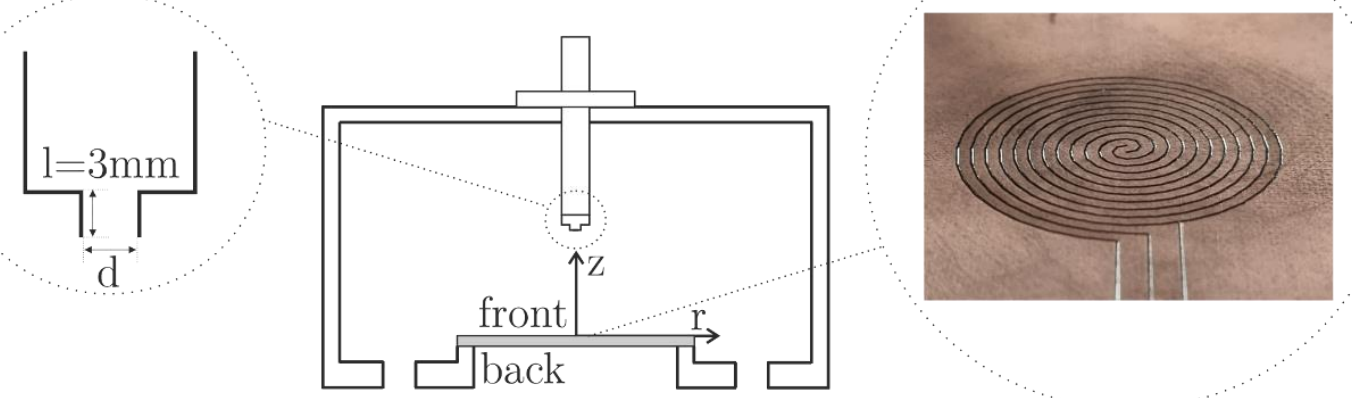

Fig. 2. More detailed scheme of the nozzle and the test section, with a picture of the copper resistance.

This target is a PTFE (Teflon) plate $(0.8 \mathrm{~mm}$ thick), covered with a thin copper foil $(35 \mu \mathrm{m}$ thick) engraved to form a spiral-shaped electric track on the side impinged by the jet. Each copper track is $1.05 \mathrm{~mm}$ wide and the distance between the spiral arms is $0.2 \mathrm{~mm}$, resulting in $84 \%$ coverage of the surface. A $360 \mathrm{~V} / 30 \mathrm{~A} / 1800 \mathrm{~W}$ DC power supply permits choice of the heat flux due to Joule effect in the heating resistance thereby created. This heating technique 
was also used in previous experimental studies such as [26,27]. Measurements made with natural convection conditions showed good homogeneity of the temperatures over the work area (and also the heating flux). The opposite side of the plate is painted with high-emissivity black paint $(\varepsilon=0.95 \pm 0.02)$ to conduct thermographic measurements using an infrared camera (FLIR SC7000). As the plate faces down, a golden mirror positioned with a $45^{\circ}$ angle is required to provide optical access to the plate by the camera. The tank and the entire piping system are thermally insulated from the environment to minimize heat loss before injection. Two type-K thermocouples placed on both sides of the apparatus indicate the ambient temperature by averaging their data. All sensors are connected to a data acquisition module (Agilent 34970A) that communicates with a LabVIEW program, calculating parameters such as injection Prandtl and Reynolds numbers. This program also allows remote control of the thermostat and DC supplies, thereby ensuring a live check of these parameters.

In addition, visualizations were carried out so as to characterize the flow (estimating the hydraulic jump radius for example). To do so, the target plate was replaced by a transparent polycarbonate not heated plate. A similar apparatus including a camera and a mirror was used.

\section{Experimental procedure}

Based on Newton's law of cooling, the convective heat transfer coefficient induced by the jet is defined as $h=\varphi_{\text {conv }} /\left(T_{w}-T_{\text {ref }}\right)$, where $\varphi_{\text {conv }}$ is the convective flux between the jet and the impinged plate, $T_{w}$ the front wall temperature and $T_{r e f}$ the fluid reference temperature. Due to possible viscous heat dissipation in the boundary layer of the impinging liquid jets, especially oil jets, use of the injection temperature $T_{i n j}$ as a reference may not be appropriate, as the reference temperature $T_{\text {ref }}$ could be superior to $T_{i n j}$. Indeed, many authors [15-19,25] have used the adiabatic wall temperature $T_{a w}$ to represent the fluid temperature over the plate (this point will be discussed in more detail in section 4.1). To determine this temperature, measurements were made for each configuration without heating the target plate with copper resistance. By doing so, the convective heat flux between the target plate and the jet, equal to the heat flux evacuated into ambient air on the backside of the impinged plate, was negligible, and the plate could be considered adiabatic; calculations showed that neglect of this flux led to an error on $T_{a w}$ below $0.19 \mathrm{~K}$ in the worst case, $(0.04 \mathrm{~K}$ at stagnation point). This temperature 
was consequently assumed to be the adiabatic wall temperature, and used as reference to calculate $h$ :

$$
h=\frac{\varphi_{c o n v}}{T_{w}-T_{a w}}
$$

To determine the convective flux and wall temperature induced by the impinging jet, a measurement technique applying infrared thermometry was used in this study, providing higher spatial resolution of temperature than thermocouples and not requiring mechanical probing, which can disturb the system. For each measurement, the jet is activated, and the target zone is heated using the cooper circuit mentioned above. After thermal equilibrium is reached, the mean temperatures of 300 thermographic images, recorded over $15 \mathrm{~s}$, are calculated for each pixel. As measurements have to be made on the back side of the plate, the couple $\left(\varphi_{\text {conv }} ; T_{w}\right)$ is calculated from backside temperatures $T_{\text {backside }}$. Considering the low thermal conductivity of PTFE $\left(\lambda_{s}=0.3 \mathrm{~W} \cdot \mathrm{m}^{-1} \cdot \mathrm{K}^{-1}\right)$ and the small thickness of the plate $(e=0.8 \mathrm{~mm})$, a onedimensional flux across the plate was assumed. This hypothesis was compared to a more complex inverse method and provided satisfactory results (the error on $T_{w}$ is about $2 \%$ ). The copper resistance situated on the front side of the plate produces electric heating flux $\varphi_{\text {elec }}$. Flux is calculated by taking into account the electric intensity imposed in the circuit and the thermal variation of copper electric resistance. As a result, $\varphi_{c o n v}$ can be deduced by subtracting heat loss $\varphi_{\text {loss }}$ (radiation and natural convection on the back side of the plate) from $\varphi_{\text {elec }}$.

$$
\begin{gathered}
\varphi_{\text {loss }}=h_{\text {nat }}\left(T_{\text {backside }}-T_{\text {amb }}\right)+\sigma \varepsilon\left(T_{\text {backside }}{ }^{4}-T_{\text {amb }}{ }^{4}\right) \\
\varphi_{\text {conv }}=\varphi_{\text {elec }}-\varphi_{\text {loss }}
\end{gathered}
$$

The mean temperature of two type-K thermocouples determines the ambient temperature $T_{a m b}$ necessary for these calculations. The natural convective coefficient $h_{\text {nat }}$ was experimentally estimated to be equal to $2 \mathrm{~W} / \mathrm{m}^{2} . \mathrm{K}$ with an uncertainty of $\pm 50 \%$. In all the cases in this study, the sum of heat loss represented less than $2 \%$ of $\varphi_{c o n v}$. This can be explained by the higher cooling efficiency of forced convection employing liquid jets compared to natural convection. Having calculated the heat flux lost at the back of the plate, $T_{w}$ can be determined by considering thermal conduction into the plate.

$$
T_{w}=T_{\text {backside }}+\varphi_{\text {loss }} \frac{e}{\lambda_{s}}
$$


Hence, the Nusselt number can be defined from equation (1) as follows, for each pixel on the front side of the plane:

$$
N u=d \frac{h}{\lambda_{f}}=d \frac{\varphi_{c o n v}}{\lambda_{f}\left(T_{w}-T_{a w}\right)}
$$

Where $\lambda_{f}$ is the fluid thermal conductivity evaluated at injection temperature

When impinging on the target, the flow spreads radially on the surface. Consequently, the local convective heat transfer coefficient can be described along a radial axis. For each measurement made in this study, data result from the averaging at a given distance $r / d$ to impinging point. Uncertainties are calculated using the approach of Coleman and Steele [28], by taking into account errors due to ambient and reference temperature, to emissivity, to oil properties, and to electrical, radiative and convective fluxes. The maximum uncertainty of the Nusselt number measurements was calculated to be $\pm 12.1 \%$. It was calculated for the smallest nozzle diameter, at stagnation point, where the temperature difference between the wall and the jet is minimal. For comparison purposes, the maximum uncertainty obtained at the end of the domain, where temperature difference is the highest, was $\pm 7.4 \%$. All in all, $95 \%$ of data points present uncertainty under $\pm 8.8 \%$. Relative errors in this study are estimated to be under $\pm 4.4 \%$.

\section{Preliminary results and discussions}

\subsection{Adiabatic wall temperature}

As mentioned above, adiabatic wall temperature $T_{a w}$ was systematically measured before heating the plate to serve as reference temperature to calculate $h$, as heat dissipation could lead to a temperature slightly higher than the injection temperature. In this study, the measured temperature was generally close to $T_{i n j}$, as viscous heat dissipation was almost slight enough to be neglected (using $T_{i n j}$ as reference instead of $T_{a w}$ generally leads to an error under 3.4\% on $\mathrm{Nu}$ ). Nevertheless, in some cases involving high Prandtl numbers and high injection velocities, differences between $T_{a w}$ and $T_{i n j}$ were found (up to $2^{\circ} \mathrm{C}$ difference, leading to an error around $6.7 \%$ on $\mathrm{Nu}$ in the worst case). Thus, the choice was made to systematically use the $T_{a w}$ value as reference. A typical result is shown on figure 3. Non-monotonic radial evolution of the adiabatic wall temperature was observed; a sharp increase of $T_{a w}$ from stagnation point leads to a maximum located near $r / d=1.5$. After this point, adiabatic wall temperature decreases slightly. This radial evolution is consistent with the conclusions of Ma et al. [18], who found a local maximum at the same radius. When impinging the plate, normal speed drops in favour of radial speed in the region near stagnation, resulting in a peak of the 
heat dissipation. Then, the fluid film becomes slower and the viscous heat dissipations decrease. Moreover, the temperatures within the film are gradually homogenized. As a result, the adiabatic temperature, representing the near wall temperature of the fluid, slightly decreases.

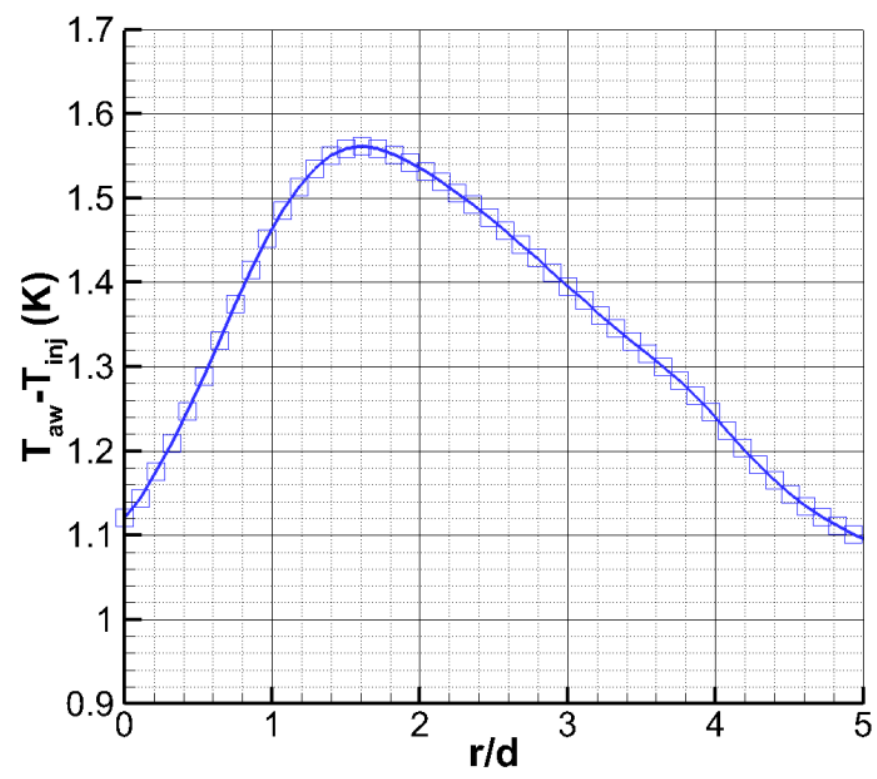

Fig. 3. Radial variation of the temperature difference of adiabatic wall temperature to injection temperature. $\operatorname{Pr}=737, \operatorname{Re}=660, d=2 \mathrm{~mm}, \mathrm{z} / \mathrm{d}=10$

\subsection{Effect of the heating flux}

For each configuration, 6 different heating fluxes were imposed on the target surface, making sure not to exceed the maximum temperature supported by the plate and maintaining a temperature difference between the fluid and the plate sufficient to limit errors in convective flux calculations, resulting in an imposed electric flux $\varphi_{\text {elec }}$ ranging from 31 to $340 \mathrm{~kW} / \mathrm{m}^{2}$. Initial analysis of the results showed clear dependence of measured convective transfer coefficient on surface heating conditions. Figure 4 illustrates a tendency found in all configurations. Near the stagnation zone $(r / d<1)$, the relative difference between the curves remains quite small (more or less equal to uncertainty measurements), but it gradually increases with $r / d$. Even though discrepancies in the stagnation zone can be explained by experimental uncertainties, as the term $\left(T_{w}-T_{a w}\right)$ becomes smaller for low heating power, variations obtained at larger radii are much larger than the relative uncertainties between curves. Since results appeared to be dependent on imposed heat flux conditions over the plate, better understanding of the phenomenon and development of a methodology permitting comparison between results were required; the effects of injection conditions ( $R e, P r$, etc.) had to be examined independently of boundary condition choices. 


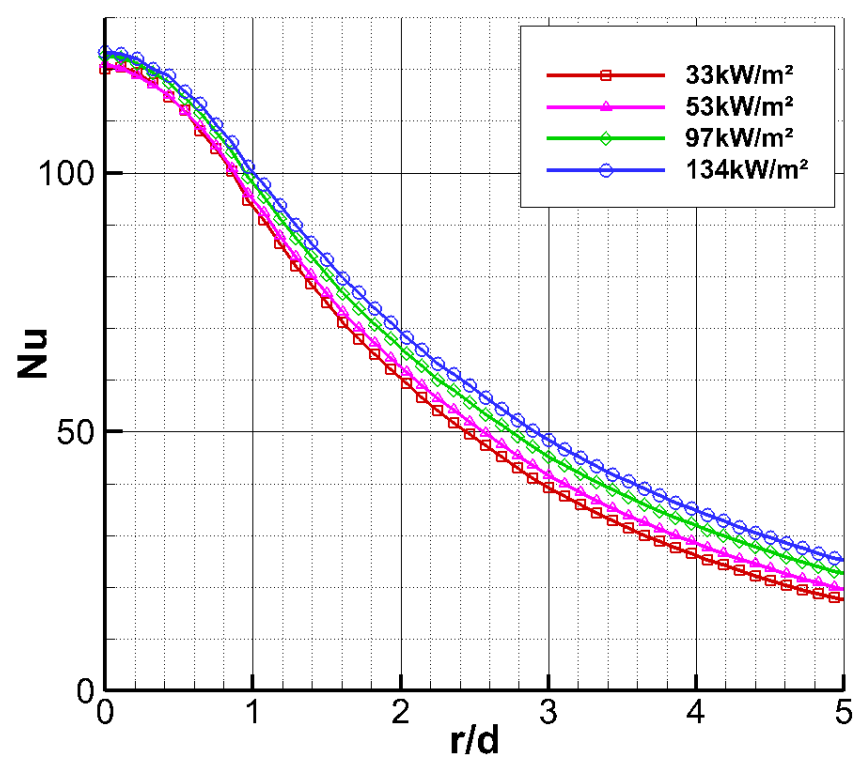

Fig. 4. Illustration of effect of mean surface heating flux on local Nusselt number. $P r=925$, $R e=230, d=2 \mathrm{~mm}, z / d=10$

Other studies have encountered this phenomenon using oil as working fluid. In their recent works on electric machine stator cooling, Kekelia et al. [29] highlighted the influence of surface temperature, which could be linked to heating flux. They found a relative difference on mean Nusselt number as high as $15 \%$ between a $90^{\circ} \mathrm{C}$ and a $120^{\circ} \mathrm{C}$ imposed condition on the target. This effect might be due to the slight change of oil properties produced by the warming of the thin liquid film along the hot plate. In fact, significant changes of viscosity near the plate are conceivable, especially with heat flux densities such as those studied in the present survey (cf. above). Viscosity is strongly dependent on temperature for lubricant oils at ambient conditions; as an example, the transition from $40^{\circ} \mathrm{C}$ to $20^{\circ} \mathrm{C}$ with the oil tested in the present survey induces a rise in dynamic viscosity of more than $120 \%$. In comparison, thermal diffusivity $(\lambda / \rho C p)$ occasions only a 5\% drop. It could be assumed that the drop of viscosity caused by film warming induces a slight rise of the local Reynolds number, which would suffice to affect heat exchanges. This phenomenon was pointed out by Sung et al. [30] numerically, even for a water film flowing over a hot plane; viscosity drop was sizable enough to significantly affect the shape of the free surface.

This observation is coherent with the average Nusselt correlations of some authors (Metzger et al. [15], Leland and Pais [17], Liu et al. [19], Soltis and Sangeorzan [25]), who have shown dependencies on a dimensionless term: $\mu_{w} / \mu_{a w}$, the ratios of dynamic viscosity evaluated at wall temperature and at adiabatic wall temperature (cf. section 3). Injection parameters such as 
Reynolds and Prandtl numbers have been evaluated at film temperature (mean value of fluid temperature at injection and wall temperature).

Nevertheless, these works did not provide local results; only mean values of Nusselt number and temperatures were considered (usually with almost uniform surface temperatures). In the present study, which deals with local data and imposes conditions closer to uniform flux, estimation of the local fluid temperature and local viscosity variations on the surface of the plate remains problematic. In industrial applications, the parameter $\mu_{w} / \mu_{a w}$ is hard to estimate and working with injection Prandtl and Reynolds numbers is more convenient. That is why a different operational methodology will be proposed to account for film warm-up and facilitate comparison between results.

By plotting the local Nusselt number obtained with several heat fluxes at fixed radial position (one example is shown on Figure 5), linear dependency of $\mathrm{Nu}$ on the convected flux $\varphi_{\text {conv }}$ was highlighted. These empirical observations suggest a formula for local heat transfer coefficient at a fixed r/d position:

$$
N u=\alpha \varphi_{c o n v}+N u_{\varphi=0}
$$

Where $\alpha$ and $N u_{\varphi=0}$ are two local values obtained by regression. They provide good agreement with observations as they fit $99 \%$ of experimental data points within a $\pm 1.9 \%$ range. $N u_{\varphi=0}$ represents the local Nusselt number that would be obtained if the plate did not heat up the oil film, which would consequently remain at adiabatic wall temperature. The term $\alpha \varphi_{\text {conv }}$ reflects the increase of the convective transfer coefficient due to oil property changes caused by heating of the oil film. 


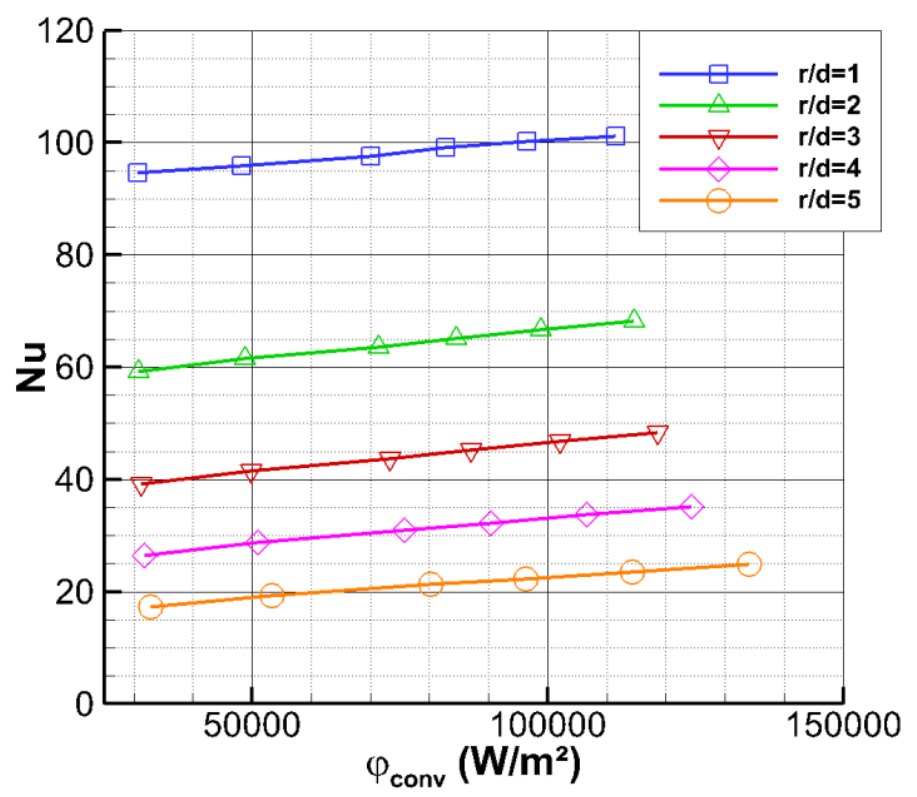

Fig. 5. Effect of surface heat flux on Nusselt number for several radius positions. $P r=925$, $R e=230, d=2 \mathrm{~mm}, z / d=10$

In fact, the rise of the mean temperature $\Delta T$ in the oil film can be estimated using the following equation, considering the mass flow $\dot{m}$ flowing over the heating surface $S$ :

$$
\Delta T=S \frac{\varphi_{\text {conv }}}{\dot{m} C p}
$$

Regarding present data, this leads in the worst case to a mean film temperature increase between the impact and the end of the work area of about $2.5^{\circ} \mathrm{C}$. However, the oil film does not heat up uniformly: the thermal diffusivity of the oil is low enough to assume that the thermal effect of the heating plate is probably limited to the vicinity of the plate (thermal boundary layer which is quite small considering the Prandtl number). This results in notable changes in the properties of the oil, particularly a significant drop in viscosity as mentioned above and consequently in a rise of the local Reynolds number and therefore of the heat transfers.

Moreover, the coefficient $\alpha$ appeared to be dependent on injection conditions and radial direction over the plate. To facilitate comparisons between different cases, equation (6) should be rewritten as follows:

$$
\frac{N u}{N u_{\varphi=0}}=\frac{\alpha}{N u_{\varphi=0}} \varphi_{c o n v}+1=\beta \varphi_{c o n v}+1
$$

Bringing together the data obtained with all 41 injection configurations, with heat flux conditions ranging from 31 to $340 \mathrm{~kW} / \mathrm{m}^{2}$, the local value of $\beta=\alpha / N u_{\varphi=0}$ showed 
dependency on Reynolds number $R e$, injector diameter $d$ and distance from stagnation $r$. Using a least squares regression method, equation (9) was obtained:

$$
\beta=2.35 \times 10^{-5} \frac{r}{d} R e^{-0.59}\left(\frac{d}{d_{\text {ref }}}\right)^{0.65}
$$

It correlates $95 \%$ of data within $\pm 28 \%$ for $r / d>2.5$ (Figure 6 ). For smaller radii, especially near the stagnation zone $(r / d<1)$, correlation was less relevant as this area is subject to more experimental uncertainties and, as mentioned above, is only slightly affected by heating flux variations. However, it was assumed that at stagnation point, local value of $\beta$ is equal to zero, and that $N u=N u_{\varphi=0}$, as the fluid temperature is equal by definition to adiabatic wall temperature $T_{a w}$; the fluid has yet to be heated by the plate. The radial dependency of $\beta$ was to be expected, insofar as fluid properties evolve more and more, when the flow is in contact with the plate and warms up. Under fixed injection parameters, approximating $\beta$ by a simple linear function of $r / d$ gives reasonably good results. However, the effect of the injection parameters, expressed by $R e^{-0.59}$ and $\left(d / d_{\text {ref }}\right)^{0.65}$ dependencies is more complex. Greater effects are observed for low Reynolds numbers. It can be assumed that when considering larger Reynolds numbers, inertial forces prevail on viscosity forces and therefore viscosity changes are less relevant. Dependence on the diameter could be explained by considering that larger diameters lead to lower fluid velocities in the vicinity of the plate for a constant Reynolds number. Therefore the liquid which flows on the plate is renewed less rapidly and is more affected by the warming. Additional studies would be necessary to better understand the phenomenon. 


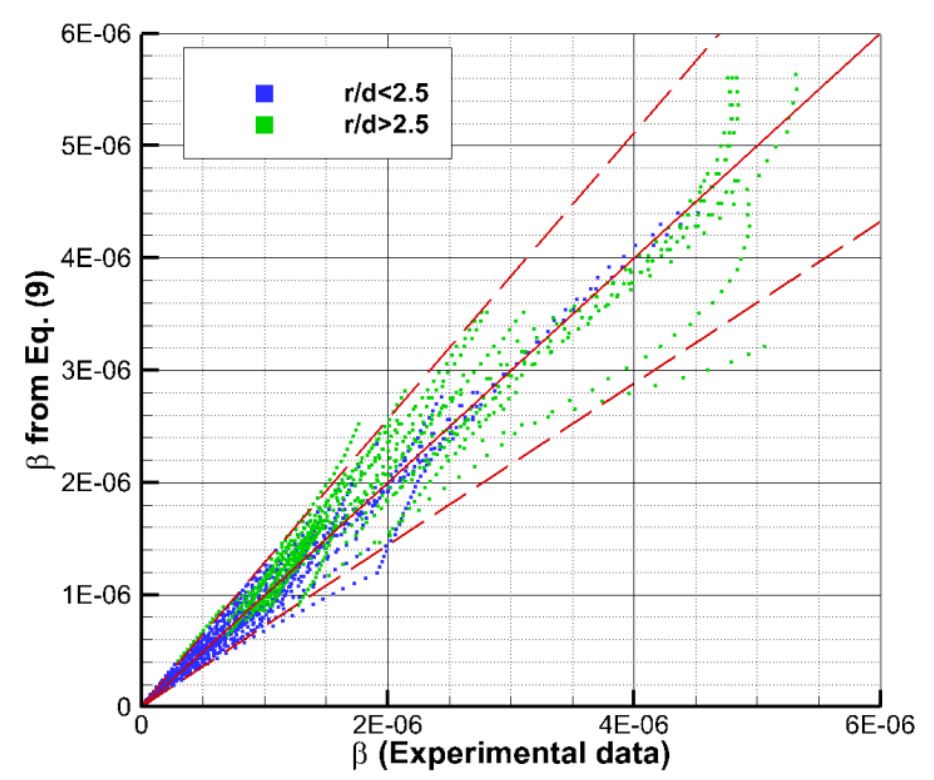

Fig. 6. Comparison of all data to the correlation (Eq. 9). Dashed lines represents an error of $\pm 28 \%$.

Hence, the above equations can calculate $N u_{\varphi=0}$ for all configurations. This value will be used to compare results and study the influence of the different parameters over Nusselt number. Therefore, all Nusselt numbers presented in the next sections will be $N u_{\varphi=0}$, calculated from equation (8). Injection parameters such as Reynolds and Prandtl numbers will be evaluated at injection temperature $T_{i n j}$. In brief, the results and correlations provided below will be valid for a hypothesized non-heated film fluid. The effect of the heat flux is set aside, facilitating precise comparison of data. Equations (8) and (9) will then correct the values given below, taking into account the heating of the film for a convected flux $\varphi_{\text {conv }}$.

\section{Results and discussions}

\section{1 local Nusselt number analysis}

Figures 7 and 8 illustrate the effect of an increase of Prandtl or Reynolds number when the other parameters are set. In accordance with the literature, higher injection Prandtl and Reynolds numbers lead to better exchanges throughout the plate. Increasing jet velocity and Reynolds number enhances wall friction forces and ensures better cooling. Higher Prandtl numbers are associated with thinner thermal boundary layers, which prioritize convective transfers over diffusion. 


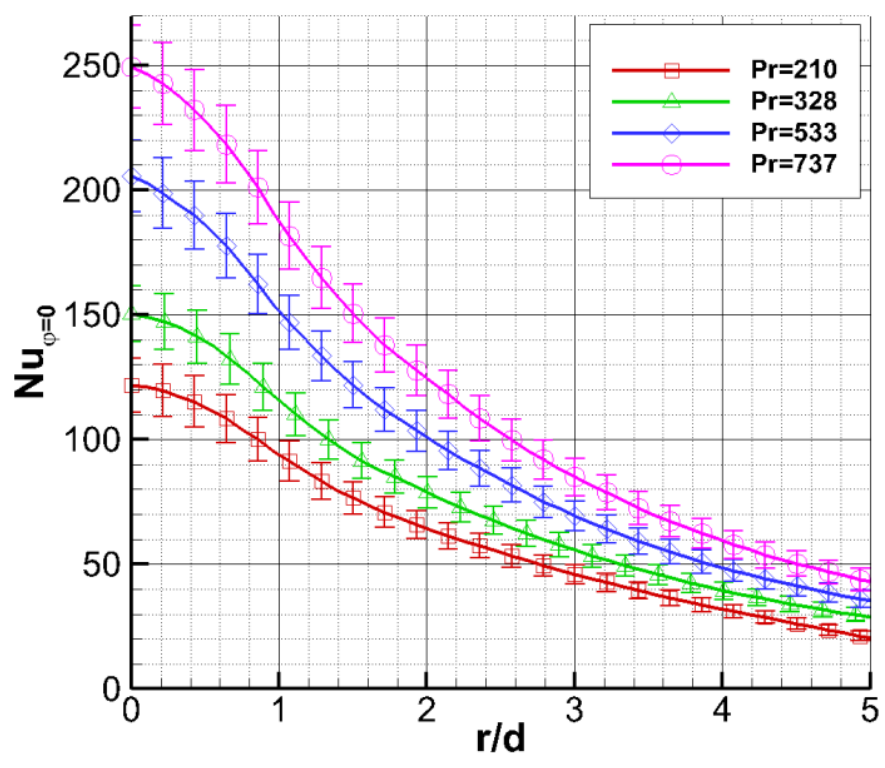

Fig. 7. Illustration of local Nusselt number dependence on Prandtl number. Re $=660, d=2$ $\mathrm{mm}, z / d=10$

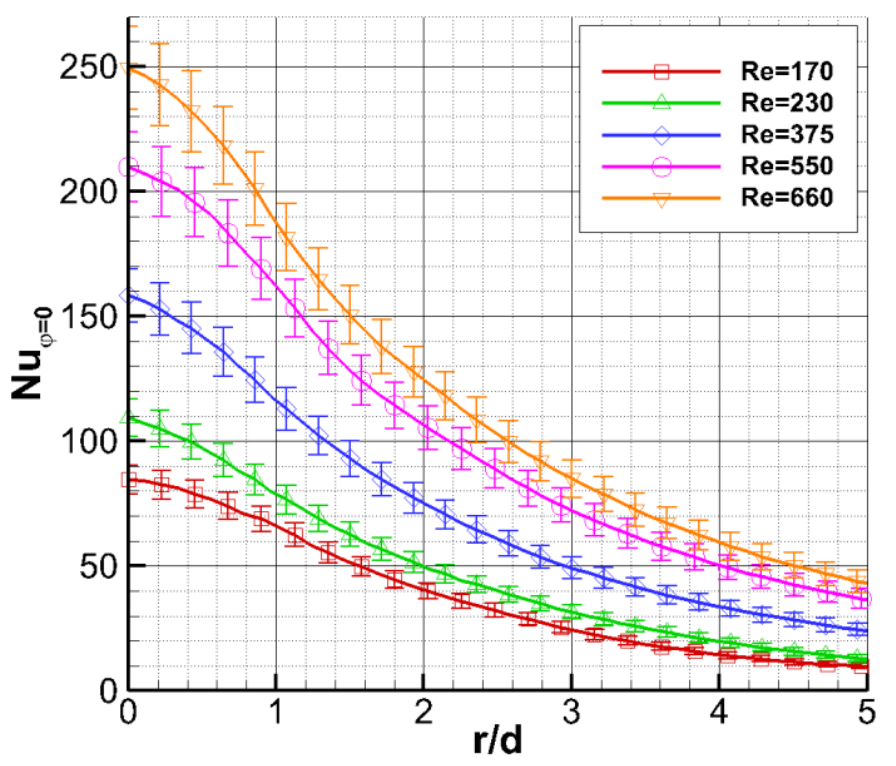

Fig. 8. Illustration of local Nusselt number dependence on Reynolds number. Pr $=737, d=$ $2 \mathrm{~mm}, z / d=10$

Heat exchanges are maximal at stagnation point when the thermal boundary layer depth is close to zero, and they gradually decrease in the radial direction as the boundary layer grows and the film spreads over the plate and loses speed. To facilitate comparison between curves, the data plotted on figure 8 were divided on figure 9 by stagnation value. After this maximum Nusselt 
located at impact point, a sharp drop occurs within $0.5<r / d<1.5$ and an inflexion point can be identified near $r / d=1.5$. This results in a fall of about $50 \%$ of the Nusselt number value between the stagnation point and two diameters further. This asymptotic change might be explained by variation of the radial speed of the flow in the film layer. The maximum speed was measured by Baonga et al. [11] at around $2<r / d<4$ and $r / d=2.5$ by Stevens and Webb [10] for water jets. After this point, radial velocity diminishes and thermal exchanges decay with a gentler slope. As noted by Ma et al. [18] with oil, normalization by stagnation Nusselt number successfully collapses data in the stagnation area $(r / d<2)$, whereas for larger radii $(r / d>2)$, lower Reynolds numbers induce a slightly steeper decrease of heat exchanges. Weak dependence on Reynolds number will be considered later for local Nusselt number correlations (section 5.3).

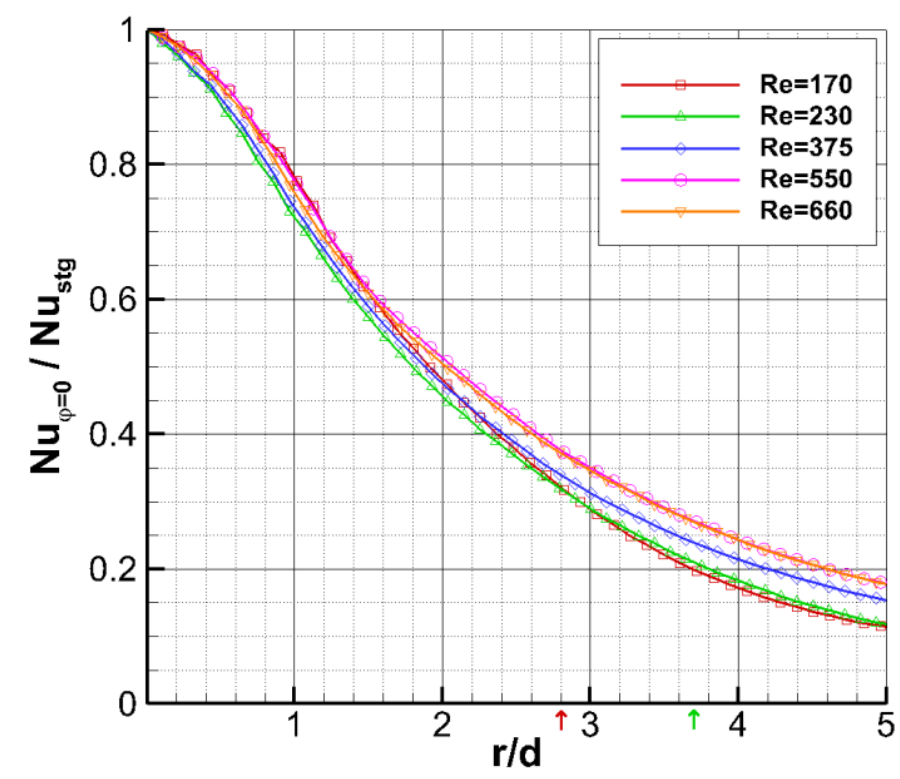

Fig. 9. Local Nusselt number divided by stagnation value for some Reynolds numbers. Arrows indicate measured hydraulic jump position for $\operatorname{Re}=170$ and $\operatorname{Re}=230 . \operatorname{Pr}=737, d=$ $2 \mathrm{~mm}, z / d=10$

In addition to thermal measurements, radial position of the hydraulic jump (promptly increased film thickness) was determined in some cases using a camera. As an example, for configurations illustrated by figures 8 and 9 , radial position of the jump was measured to occur near $r / d=$ 2.8 for $R e=170$ and $r / d=3.7$ for $R e=230$. Nevertheless, no effect of the hydraulic jump was clearly identified in heat exchanges. The same observations were made for the different cases considered in this study, despite the expected drop in flow velocity. Considering the high 
$\operatorname{Pr}$ number, the thermal layer is very thin, and it can be assumed that the velocity profiles in the thermal boundary layer are not sufficiently affected by the jump to produce any effect on heat transfers.

Variations of the nozzle diameter at constant injection Prandtl and Reynolds numbers were also considered. Figure 10 (a) shows a representative example of local Nusselt value for 3 different nozzle diameters using the normalized radius from stagnation. Figure 10 (b) illustrates the effect of a change of diameter for a given radius (more convenient for industrial application). Significant differences were observed, particularly in the stagnation zone. Away from stagnation point, the difference between curves is generally reduced when considering normalized distance from stagnation. These trends in diameter are similar from those found by others studies [11,14,17,19,25] which used various liquids (water, oil...) and injector geometries (pipe or orifice nozzle). These observations tend to confirm that before impingement, a change of injection diameter affects the dynamic of the flow. Consequently, heat transfers in the stagnation area are strongly dependent on this parameter, but as the distance from the impact point increases, return to more classic behaviour is observed, with liquid film flowing over a plate, and Nusselt profiles tend to merge.
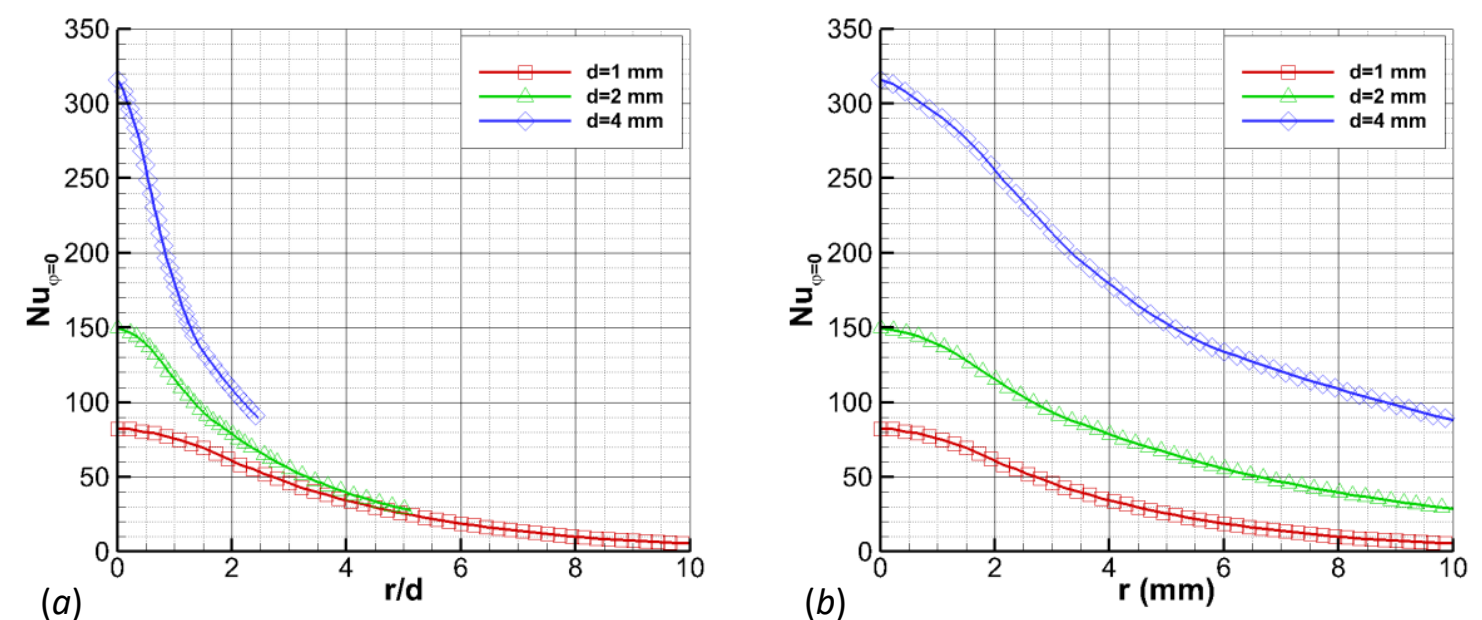

Fig. 10. Illustration of local Nusselt number dependence on injection diameter (normalized distance (a) and non-normalized distance (b) from stagnation point). $\operatorname{Pr}=328, \operatorname{Re}=660$,

$$
z / d=10
$$

These observations show that, as discussed in the introduction, the Reynolds number is not sufficient to fully express the influence of the injector diameter on heat transfer for liquid jets. Nozzle exit velocity profile might be affected differently depending on the diameter, leading to higher centreline velocities with larger diameters. Confirmation of this hypothesis with velocity 
measurements would be of great help, but is difficult given the nature of the fluid. By the way, as the injection length is not modified with diameter in this study, it is possible that part of this influence is due to this modification of the injection.

Finally, as shown on figure 11, measurements were made for 3 different nozzle-to-target distances $(z / d=5 ; 10 ; 20)$. In agreement with the literature $[11,13,14,17-19]$, no particular dependencies were found within this range, as the distance is not sufficient to be subject to gravitational effects $(z / d>20)$, or on the contrary is too high to disturb the flow near stagnation $(z / d<1)$. Momentum ratio between the liquid jet and the ambient air is too large, and shearing forces on the interface of air and the viscous fluid are consequently too weak to disturb the flow. The observed fluctuations clearly reflect experimental uncertainties. No effect was found beyond the stagnation zone; local Nusselt number profiles were similar for fixed Reynolds, Prandtl and nozzle diameter.

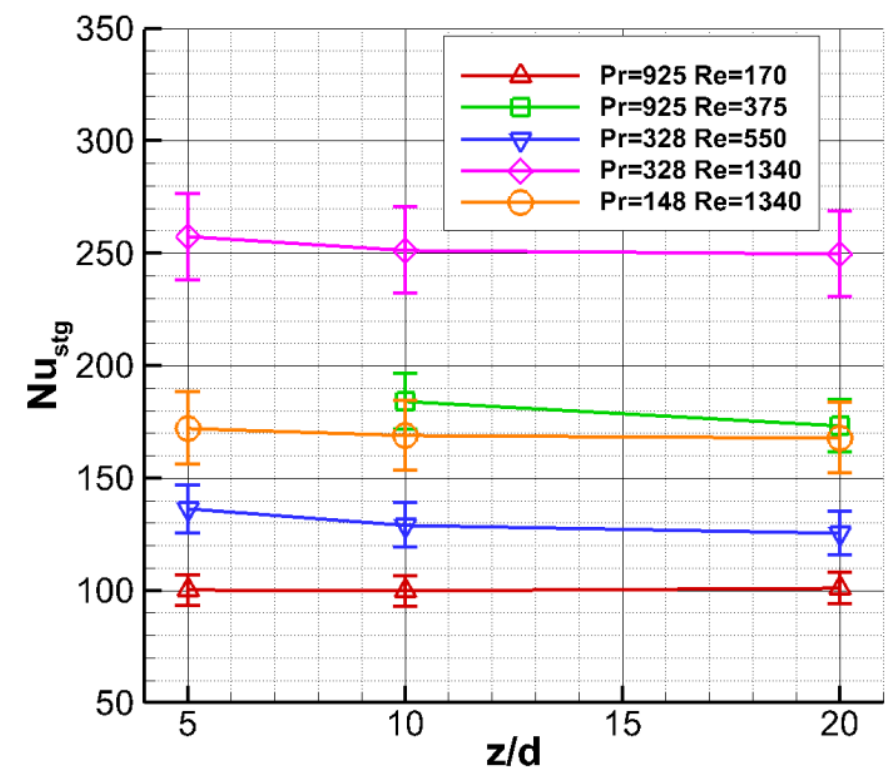

Fig. 11. Stagnation Nusselt number for three different nozzle-to-target distance and various Reynolds and Prandtl number couples. $d=2 \mathrm{~mm}$

\subsection{Stagnation Nusselt number correlation}

As mentioned above, many injection parameters were considered in this study, and they influenced heat transfer efficiency. In agreement with the literature, higher injection Prandtl and Reynolds numbers lead to higher Nusselt number. The pronounced influence of nozzle diameter was also identified. By gathering these data, two correlations for the stagnation Nusselt number $N u_{s t g}$ were calculated using a least squares technique. However, writing down 
a proper set of equations modelling the splashing of the oil jet on the plate and leading to a characteristic dimensionless quantity linked to the nozzle diameter $d$ is quite a difficult task. In the present work, correlations with dimensional parameter $d$ and an arbitrary chosen $d_{r e f}$ are suggested. Similarly to Elison and Webb [13] or Leland and Pais [17], who used water and oil respectively, a distinction was made between laminar and turbulent jets. Transition between these two regimes was found to occur within $500<R e<700$, as shown on figure 12 .

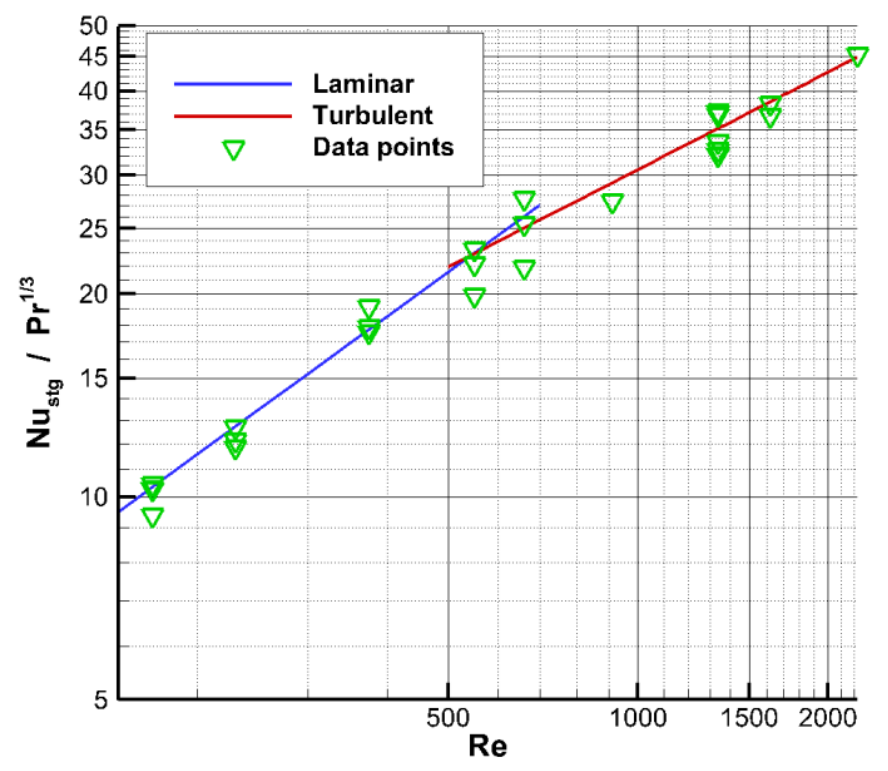

Fig. 12. Correlation of stagnation Nusselt number data using equations (10) and (11). $d=$ $2 \mathrm{~mm}$

This early transition (compared to the one founded by Leland and Pais [17] with oil : $R e=$ $800-1000$ ) may be explained by the injection geometry (sudden change of section $3 \mathrm{~mm}$ before injection). The following equations are obtained:

For initially laminar jet $(170<R e<500)$ :

$$
N u_{s t g}=0.315 \operatorname{Re}^{0.68} \operatorname{Pr}^{\frac{1}{3}}\left(\frac{d}{d_{\text {ref }}}\right)^{0.98}
$$

For initially turbulent jet $(700<R e<2225)$ :

$$
N u_{s t g}=1.11 \operatorname{Re}^{0.48} \operatorname{Pr}^{\frac{1}{3}}\left(\frac{d}{d_{\text {ref }}}\right)^{0.94}
$$

These two equations fit experimental data with a mean error of $3.1 \%$ and $5.7 \%$ for the laminar and turbulent regimes respectively (figure 13). 


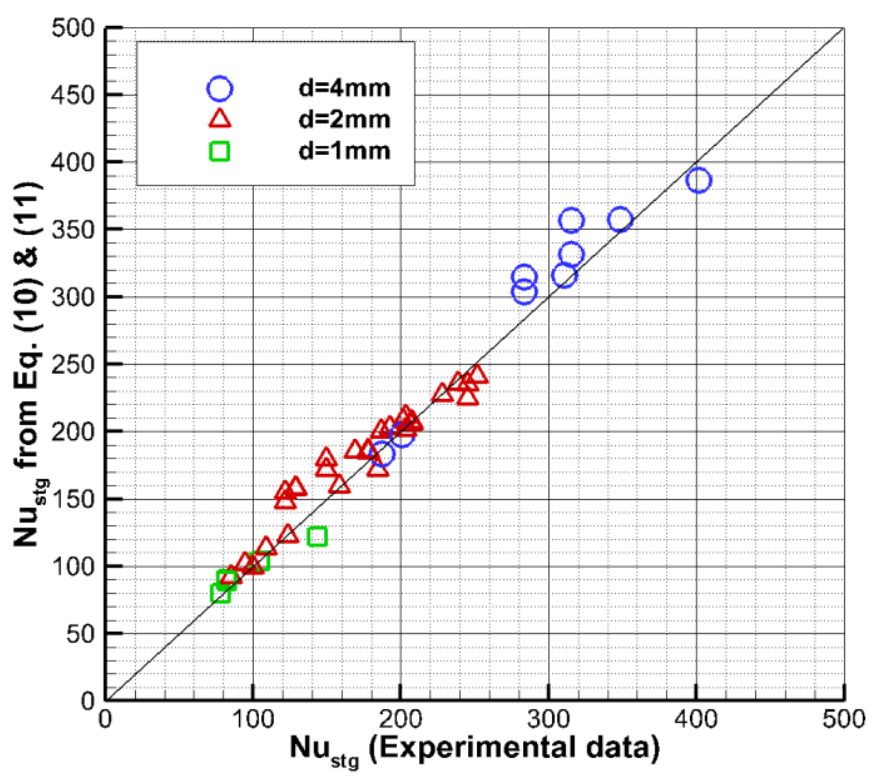

Fig. 13. Comparison of all data to the correlation (Eq. 10 and 11).

Exponent on Prandtl number was equal to $1 / 3$, as this value is widely used in literature and provides good agreement with the present results, even when considering larger Prandtl numbers; no specific behaviour was found for highly viscous fluids, even if some authors suggested less dependence $\left(\mathrm{Pr}^{0.239-0.32}\right)$, or stronger dependence $\left(\mathrm{Pr}^{0.4}\right)$ Easter et al. [22]. Reynolds exponents were close to those obtained by Elison and Webb [13] with water or Leland and Pais [17] with oil. Good agreement was also found with Easter et al. [22], who used a comparable range of Prandtl and Reynolds $(100<R e<4500,90<\operatorname{Pr}<750)$, but bigger nozzle-to-plate distances $(45<z / d<95)$. They proposed $R e^{0.652}$ dependence without distinction between flow regimes.

Nozzle diameter dependency was found to be almost linear. As a result, even if Nusselt values are strongly dependent on this parameter, only slightly lower values of the heat transfer coefficient h were found at constant $\mathrm{Pr}$ and $R e$ when increasing the diameter. By comparing the two flow regimes, no substantial difference on this dependency was noted.

\subsection{Local Nusselt number correlation}

To correlate heat exchange distribution over the plate, the normalized local Nusselt $\mathrm{Nu} / \mathrm{Nu} u_{\text {stg }}$ was considered. As mentioned before, a Reynolds and nozzle diameter dependence for this profile was identified. The only experimental survey including local data for oil jets to our knowledge, conducted by Ma et al. [18], also noted a Reynolds dependence (their study focused on only one injector diameter). Consequently, a similar formulation was chosen to correlate the 
local normalized Nusselt obtained in this survey, adding a term to take into account the variation of diameter:

$$
\frac{N u}{N u_{s t g}}=\frac{1}{1+0.0664\left(\frac{r}{d}\right)^{1.8}}(0.00148 R e)^{0.035 \frac{r}{d}}\left(2.54 \frac{d}{d_{r e f}}\right)^{-0.25 \frac{r}{d}}
$$

This equation provides good results; it correlates $95 \%$ of data within $\pm 22 \%$. Moreover, coefficients are very similar to those found by Ma et al. [18].

It should be reiterated that this Nusselt profile corresponds to non-heated oil film. To take into consideration the warming of the oil film over a hot plate, equations (8) and (9) are applicable.

\subsection{Mean Nusselt number correlation}

By proceeding similarly, it is possible to calculate mean Nusselt number by integrating the curve up to a fixed radius. The following equation correlates the normalized average Nusselt number $N u_{\text {avg }} / N u_{\text {stg }}$ on a disk of radius $r / d$ :

$$
\frac{N u_{\text {avg }}}{N u_{\text {stg }}}=\frac{1}{1+0.0300\left(\frac{r}{d}\right)^{1.7}}(0.00214 R e)^{0.017 \frac{r}{d}}\left(2.76 \frac{d}{d_{r e f}}\right)^{-0.16 \frac{r}{d}}
$$

This formula correlates $95 \%$ of experimental data within $\pm 12.5 \%$. It is also possible to compare the correlations developed in the present study to determine the average Nusselt (equations (10), (11) and (13)) with the correlations found by Leland and Pais [17] with a similar range of parameters $(109<R e<8592, \quad 48<\operatorname{Pr}<445, \quad 0.67<z / d<4.14, \quad d=$ $0.51 ; 0.84 ; 1.70 \mathrm{~mm}, D=12.95 \mathrm{~mm}$ ). Good agreement was found when comparing the two correlations, as shown on figure 14. 


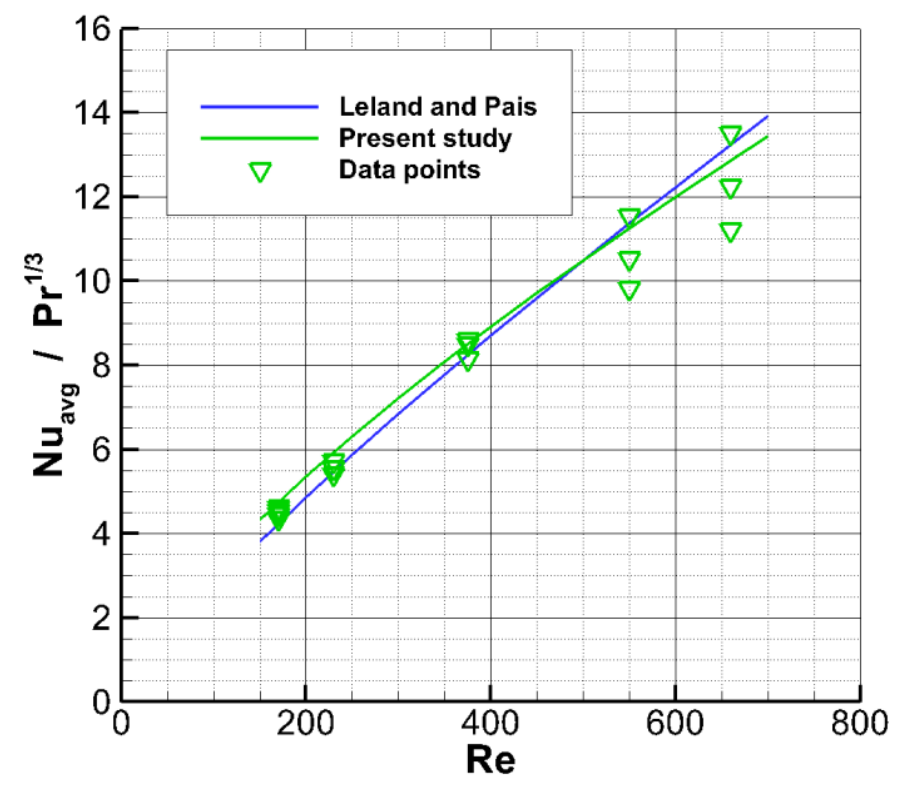

Fig. 14. Comparison between correlations developed in this survey and the one found by Leland and Pais [17] under a laminar regime. Mean Nusselt number on a disk of diameter $D=12.95 \mathrm{~mm}$. Injection diameter $d=2 \mathrm{~mm}$.

\section{Conclusions}

An experimental study was conducted to evaluate local heat transfer of a viscous oil jet impinging on a heated plate. Results showed that the oil property changes due to warming over a hot surface should be taken into account, as they induce a strong effect on heat transfers downstream of the impingement point. A methodology was proposed to take into account this phenomenon.

The classical $\operatorname{Pr}^{1 / 3}$ dependence on heat transfer showed good results for a large range of tested injection Prandtl numbers $(148<\operatorname{Pr}<925)$, in both laminar and turbulent regimes. Moreover, a strong dependency on the nozzle diameter was highlighted, as larger diameters yielded higher Nusselt numbers in the stagnation zone. This was attributed to the velocity profile at injection.

\section{Acknowledgements}

The English-language text has been reviewed and edited by an American translator, Jeffrey Arsham. His support is gratefully acknowledged. 


\section{References}

[1] T. Davin, J. Pellé, S. Harmand, R. Yu, Experimental study of oil cooling systems for electric motors, Appl. Therm. Eng. 75 (2015) 1-13. https://doi.org/10.1016/j.applthermaleng.2014.10.060.

[2] T. Davin, J. Pellé, S. Harmand, R. Yu, Motor Cooling Modeling: An Inverse Method for the Identification of Convection Coefficients, J. Therm. Sci. Eng. Appl. 9 (2017) 041009-041009-13. https://doi.org/10.1115/1.4036303.

[3] B. Assaad, K. Mikati, T.V. Tran, E. Negre, Experimental Study of Oil Cooled Induction Motor for Hybrid and Electric Vehicles, in: 2018 XIII Int. Conf. Electr. Mach. ICEM, 2018: pp. 1195-1200. https://doi.org/10.1109/ICELMACH.2018.8507058.

[4] Y. Gai, M. Kimiabeigi, Y. Chuan Chong, J.D. Widmer, X. Deng, M. Popescu, J. Goss, D.A. Staton, A. Steven, Cooling of Automotive Traction Motors: Schemes, Examples, and Computation Methods, IEEE Trans. Ind. Electron. 66 (2019) 1681-1692. https://doi.org/10.1109/TIE.2018.2835397.

[5] E.J. Watson, The radial spread of a liquid jet over a horizontal plane, J. Fluid Mech. 20 (1964) 481-499. https://doi.org/10.1017/S0022112064001367.

[6] X.S. Wang, Z. Dagan, L.M. Jiji, Heat transfer between a circular free impinging jet and a solid surface with non-uniform wall temperature or wall heat flux-1. Solution for the stagnation region, Int. J. Heat Mass Transf. 32 (1989) 1351-1360. https://doi.org/10.1016/0017-9310(89)90034-3.

[7] C.F. Ma, Y.H. Zhao, T. Masuoka, T. Gomi, Analytical study on impingement heat transfer with single-phase free-surface circular liquid jets, J. Therm. Sci. 5 (1996) 271277. https://doi.org/10.1007/BF02653234.

[8] Y.C. Chen, C.F. Ma, M. Qin, Y.X. Li, Theoretical study on impingement heat transfer with single-phase free-surface slot jets, Int. J. Heat Mass Transf. 48 (2005) 3381-3386. https://doi.org/10.1016/j.ijheatmasstransfer.2005.02.027.

[9] X. Liu, V. Lienhard J.H., J.S. Lombara, Convective Heat Transfer by Impingement of Circular Liquid Jets, J. Heat Transf. 113 (1991) 571-582. https://doi.org/10.1115/1.2910604.

[10] J. Stevens, B.W. Webb, Measurements of the Free Surface Flow Structure Under an Impinging, Free Liquid Jet, J. Heat Transf. 114 (1992) 79-84. https://doi.org/10.1115/1.2911271.

[11] J.B. Baonga, H. Louahlia-Gualous, M. Imbert, Experimental study of the hydrodynamic and heat transfer of free liquid jet impinging a flat circular heated disk - ScienceDirect, Appl. Therm. Eng. 26 (2005) 1125-1138.

[12] M.L. Hosain, R. Bel Fdhila, A. Daneryd, Heat transfer by liquid jets impinging on a hot flat surface, Appl. Energy. 164 (2016) 934-943. https://doi.org/10.1016/j.apenergy.2015.08.038.

[13] B. Elison, B.W. Webb, Local heat transfer to impinging liquid jets in the initially laminar, transitional, and turbulent regimes - ScienceDirect, Int J Heat Mass Transf. 37 (1994) 1207-1216.

[14] J. Stevens, B.W. Webb, Local Heat Transfer Coefficients Under an Axisymmetric, Single-Phase Liquid Jet, J. Heat Transf. 113 (1991) 71-78. https://doi.org/10.1115/1.2910554.

[15] D.E. Metzger, K.N. Cummings, W.A. Ruby, METZGER, D. E., CUMMINGS, K. N., et RUBY, W. A. Effects of Prandtl number on heat transfer characteristics of impinging liquid jets, in: Tokyo, Japan, 1974: pp. 20-24.

[16] H. Sun, C.F. Ma, Y.C. Chen, Prandtl number dependence of impingement heat transfer with circular free-surface liquid jets, Lnt J Heat Mass Transf. 41 (1998) 1360-1363. 
[17] J.E. Leland, M.R. Pais, Free Jet Impingement Heat Transfer of a High Prandtl Number Fluid Under Conditions of Highly Varying Properties, J. Heat Transf. 121 (1999) 592597. https://doi.org/10.1115/1.2826020.

[18] C.F. Ma, Q. Zheng, S.Y. Ko, Local heat transfer and recovery factor with impinging free-surface circular jets of transformer oil, Int. J. Heat Mass Transf. 40 (1997) 42954308. https://doi.org/10.1016/S0017-9310(97)00054-9.

[19] Y.C. Liu, Guessous L., Sangeorzan B. P., Alkidas A. C., Laboratory Experiments on Oil-Jet Cooling of Internal Combustion Engine Pistons: Area-Average Correlation of Oil-Jet Impingement Heat Transfer, J. Energy Eng. 141 (2015) C4014003. https://doi.org/10.1061/(ASCE)EY.1943-7897.0000227.

[20] L.A. Gabour, Heat transfer to turbulent and splattering impinging liquid jets, Massachusetts Institute of Technology, 1991.

[21] J.H. Lienhard, Heat transfer by impingement of circular free-surface liquid jets, Proc. 18th Natl. 7th ISHMT-ASME Heat Mass Transf. Conf. (2006).

[22] J. Easter, C. Jarrett, C. Pespisa, Y.C. Liu, A.C. Alkidas, L. Guessous, B.P. Sangeorzan, An Area-Average Correlation for Oil-Jet Cooling of Automotive Pistons, J. Heat Transf. 136 (2014). https://doi.org/10.1115/1.4027835.

[23] Y. Pan, J. Stevens, B.W. Webb, Effect of Nozzle Configuration on Transport in the Stagnation Zone of Axisymmetric, Impinging Free-Surface Liquid Jets: Part 2-Local Heat Transfer, J. Heat Transf. 114 (1992) 880-886. https://doi.org/10.1115/1.2911896.

[24] J.A. Fitzgerald, S.V. Garimella, Flow Field Effects on Heat Transfer in Confined Jet Impingement, J. Heat Transf. 119 (1997) 630-632. https://doi.org/10.1115/1.2824152.

[25] D. Soltis, B. Sangeorzan, Convective Heat Transfer in the Stagnation Zone of an Axisymmetric Upward Jet Impinging on a Stationary Flat Surface, in: American Society of Mechanical Engineers Digital Collection, 2016. https://doi.org/10.1115/IMECE201551061.

[26] M. Fénot, X.T. Trinh, E. Dorignac, Flow and heat transfer of a compressible impinging jet, Int. J. Therm. Sci. 136 (2019) 357-369. https://doi.org/10.1016/j.ijthermalsci.2018.10.035.

[27] S. Roux, M. Fénot, G. Lalizel, L.-E. Brizzi, E. Dorignac, Experimental investigation of the flow and heat transfer of an impinging jet under acoustic excitation, Int. J. Heat Mass Transf. 54 (2011) 3277-3290. https://doi.org/10.1016/j.ijheatmasstransfer.2011.03.059.

[28] H.W. Coleman, W.G. Steele, Experimentation, Validation, and Uncertainty Analysis for Engineers, John Wiley \& Sons, 2018.

[29] B. Kekelia, K. Bennion, X. Feng, G. Moreno, J.E. Cousineau, S. Narumanchi, J. Tomerlin, Surface Temperature Effect on Convective Heat Transfer Coefficients for Jet Impingement Cooling of Electric Machines With Automatic Transmission Fluid, in: American Society of Mechanical Engineers Digital Collection, 2019. https://doi.org/10.1115/IPACK2019-6457.

[30] J. Sung, H.G. Choi, J.Y. Yoo, Finite element simulation of thin liquid film flow and heat transfer including a hydraulic jump, Int. J. Numer. Methods Eng. 46 (1999) 83-101. https://doi.org/10.1002/(SICI)1097-0207(19990910)46:1<83::AID-NME665>3.0.CO;2D. 